\title{
Isolation and characterization of a variant porcine epidemic diarrhea virus in China
}

\author{
Yongfei Pan ${ }^{1+}$, Xiaoyan Tian ${ }^{1 \dagger}$, Wei $\mathrm{Li}^{1}$, Qingfeng Zhou ${ }^{1}$, Dongdong Wang ${ }^{1}$, Yingzuo Bi ${ }^{2}$, Feng Chen $^{2 *}$ \\ and Yanhua Song ${ }^{1 *}$
}

\begin{abstract}
An outbreak of diarrhea in pigs started in Guangdong, South China in January 2011. Cases were characterized by watery diarrhea, dehydration and vomiting, with $80-100 \%$ morbidity and $50-90 \%$ mortality in suckling piglets. The causative agent of the diarrhea was ultimately identified as porcine epidemic diarrhea virus (PEDV). In this study, we isolated a PEDV strain designated CHGD-01 from piglet intestines using Vero cell cultures, and its specific cytopathic effects were confirmed in susceptible cells by direct immunofluorescence testing and electron microscopy. The complete genome of CHGD-01 was shown to be 28,035 nucleotides in length, with a similar structure to that of PEDV reference strains. Phylogenetic analyses based on the whole genome revealed that CHGD-01 shared nucleotide sequence identities of 98.2-98.4\% with two other Chinese isolates reported in the same year, thus constituting a new cluster. Amino acid sequence analysis based on individual virus genes indicated a close relationship between the spike protein gene of CHGD-01 and the field strain KNU0802 in Korea. Its ORF3 and nucleoprotein genes, however, were divergent from all other sequenced PEDV isolate clusters and therefore formed a new group, suggesting a new variant PEDV isolate in China. Further studies will be required to determine the immunogenicity and pathogenicity of this new variant.
\end{abstract}

Keywords: Porcine epidemic diarrhea virus, Virus isolate, Variant

\section{Background}

Porcine epidemic diarrhea virus (PEDV) is the causative agent of porcine epidemic diarrhea (PED), an enteric disease characterized by vomiting, watery diarrhea, and dehydration in swine. This disease was first reported in feeder and grower pigs in the UK in 1971 [1], after which the virus was identified $[2,3]$. The disease has subsequently been reported in a number of European countries $[4,5]$, and more recently in China, Korea, Japan, Thailand and Vietnam [6-12].

PEDV is an enveloped RNA virus belonging to Group 1a, genus Coronavirus, family Coronaviridae, within the order Nidovirales. The viral genome is a single-stranded positive-sense RNA of approximately $28 \mathrm{~kb}$ in size, containing six genes: the replicase (Rep), spike (S), ORF3, envelope $(\mathrm{E})$, membrane $(\mathrm{M})$, and nucleoprotein $(\mathrm{N})$

\footnotetext{
*Correspondence: chenfeng1224@126.com; yanhua_song@163.com

${ }^{\dagger}$ Equal contributors

'Guangdong Wen's Group Academy, Guangdong Wen's Foodstuffs Group Co, Ltd, Xinxing, Guangdong 527400, China

${ }^{2}$ College of Animal Science, South China Agricultural University, Guangzhou 510642, China
}

genes, arranged in the order 5'-Rep-S-ORF3-E-M-N-3' [13-15]. As a coronavirus, PEDV comprises three corresponding major viral structural proteins: the S (180$220 \mathrm{kDa}), \mathrm{M}(27-32 \mathrm{kDa})$, and $\mathrm{N}(55-58 \mathrm{kDa})$ proteins $[16,17]$. The $\mathrm{S}$ protein plays a pivotal role in determining viral-cellular fusion activity and in inducing an immune response in the natural host [18-20]. The $M$ protein plays an important role in the virus-assembly process, and induces antibodies that neutralize virus in the presence of complement [21-23]. The $\mathrm{N}$ protein of coronaviruses forms a helical ribonucleoprotein with the virus genomic RNA and is the predominant antigen produced in coronavirus-infected cells, thus making it a major viral target $[24,25]$. Unlike the structural proteins, little is known about the functions of the accessory proteins. The recently-identified ORF3 gene has been demonstrated to be a potentially important determinant of virulence in this virus $[26,27]$.

PEDV can generally be controlled using the vaccine strategy, and vaccination with killed or attenuated PEDV vaccine has been widely carried out in China, where 
PED usually manifests a mild and enzootic pattern (lower mortality in suckling piglets). However, a severe acute diarrhea outbreak associated with high morbidity (80-100\%) and mortality (50-90\%) was observed in suckling piglets at approximately 10 premises in Guangdong, China, in early 2011. Although most sow herds had previously been vaccinated with both killed and attenuated PEDV vaccines based on CV777, some of these were still infected, showing transient diarrhea and anorexia, but not death. PEDV field isolates thus need to be isolated and their molecular epidemiology investigated in order to better control and prevent future PEDV outbreaks. In this study, a PEDV strain was isolated from sick piglets during this outbreak and grown in Vero cells. Molecular characterization of the virus identified it as a variant PEDV emerging in China.

\section{Results}

\section{Pathogen detection}

For PCR/RT-PCR detection of viruses, intestinal and fecal samples from 33 sick piglets were first examined for the presence of TGEV, porcine rotavirus, porcine reproductive and respiratory syndrome virus (PRRSV), PCV2, porcine kobuvirus and PBoV. All assays were negative except for three PCV2-positive samples. All specimens were subsequently examined for PEDV, and all samples were positive (data not shown).

All samples were tested for common pathogenic intestinal bacteria, such as Salmonella and pathogenic Escherichia coli, but no significant numbers of Salmonella or E. coli were isolated from sick piglets from different premises.

\section{Virus isolation and identification}

A distinct CPE was noted after seven passages in Vero cells. The CPE was characterized by cell fusion, syncytia formation and eventual detachment from the plastic surface (Figure 1b). The virus isolate designated CHGD01 was biologically cloned by three rounds of plaque purification in Vero cells prior to further virus characterization. In addition, cells tested positive by IFA (Figure 1d). Electron microscopy of a negatively-stained sample revealed the presence of medium-sized viral particles of approximately $80-120 \mathrm{~nm}$ in diameter. In some of the virions, surface projections characteristic of coronaviruses were evident (Figure 1e).

\section{Sequencing results and phylogenetic analyses}

A total of 28,035 nucleotides were determined for CHGD-01, encompassing the Rep, S, ORF3, E, M, and N proteins. Alignment of the genome sequence with those
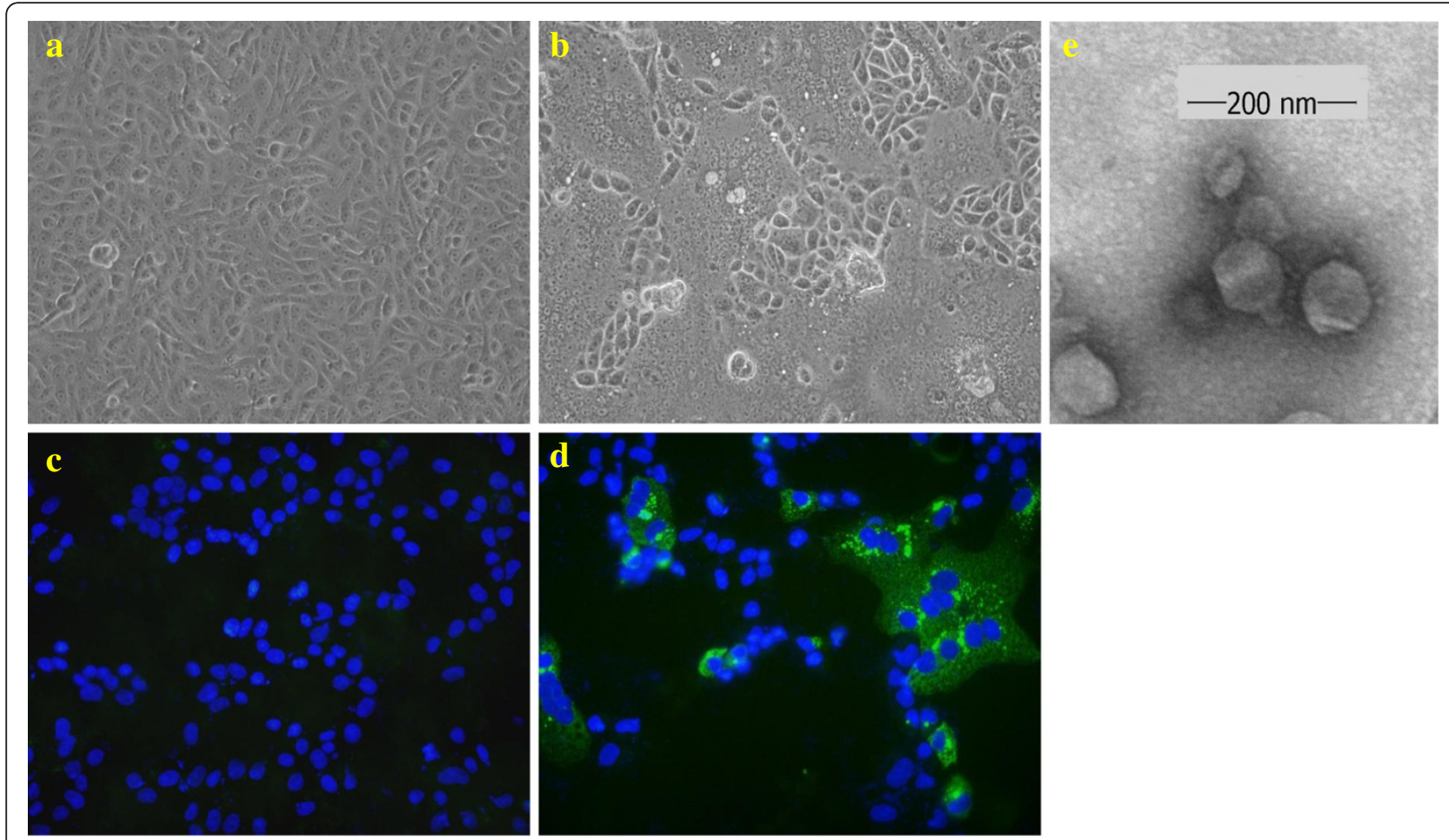

Figure 1 Identification of CHGD-01 isolate by optical microscopy, IFA assay and electron microscopy. (a) Mock-infected Vero cells. (b) CPE in Vero cells infected with PEDV-CHGD-01 showing syncytia and multiple nuclei. (c) IFA in non-infected Vero cells. (d) IFA in CHGD-01 isolateinfected Vero cells. Original magnification $\times 200$. (e) Morphology of CHGD-01 isolate under electron microscopy (negatively stained); bar =200 nm. 
of TGEV, human coronavirus-229E and PEDV reference strains available in GenBank showed the highest identity with Chinese PEDV BJ2011-1 (98.4\%), which was isolated in 2011. Phylogenetic analysis showed that CHGD01 formed a new cluster together with BJ-2011-1 and CH/FJND-3/2011.

The S protein of CHGD-01 was 4158 nucleotides long, encoding a protein of 1385 amino acids. Compared to the PEDV reference strain CV777, two insertions (in positions 61-64 and 136) and one deletion (in position 158-159) were observed (Figure 2a). It shared 92.698.2\% amino acid identity with other PEDV strains, and the highest identity with the Chinese strain BJ-2011-1. Phylogenetic analyses of the $\mathrm{S}$ protein amino acid sequences revealed that all PEDV strains in this study could be separated into two groups: CHGD-01 belonged to Group 2, which also contained the two Japanese isolates Kawahira and NK, eight Korean field strains (Chinju99, KNU-0801, KNU-0802, and KNU-0901KNU-0905) and two Chinese strains (BJ-2011-1 and CH/FJND-3/2011), which were deposited in GenBank in 2011 (Figure 3b).

The ORF3 gene of CHGD-01 was determined to be 675 nucleotides in length, coding for a polypeptide of
225 amino acids. The ORF3 gene of CHGD-01 shared 93.3-97.3\% amino acid identity with other PEDV strains, and the highest identity with the Korean virulent DR13. Based on phylogenetic analyses of the ORF3 amino acid sequences, all the PEDV strains could be divided into four groups (Figure 3c). Group 1 comprised CV777, Br1/87, SM98 and LZC strains; Group 2 consisted of vaccine strains (attenuated DR13); Group 3 was made up of eight Korean field strains and 11 Chinese strains. These results showed some similarities with the previous report by Park et al. [28]. Interestingly, phylogenetic analysis showed that CHGD-01 formed a fourth group, clearly different from other PEDV isolates. Each group had unique differences in its sequences. Group 2 had a 17-amino acid deletion (at positions 82-98), which is a marker of attenuated vaccine. ${ }^{\mathrm{F}} 80^{\mathrm{V}}$ occurred only in Group 3, while ${ }^{\mathrm{L}} 92^{\mathrm{F}}$ existed in Groups 3 and 4. Groups 2, 3 and 4 shared five specific amino acid changes $\left({ }^{\mathrm{V}} 21^{\mathrm{A}}, \mathrm{V}_{54}\right.$, $\mathrm{V}_{78} \mathrm{I},{ }^{\mathrm{F}} 79^{\mathrm{V}},{ }^{\mathrm{A}} 101^{\mathrm{T}}$ and $\left.{ }^{\mathrm{N}} 166^{\mathrm{S}}\right)$. An additional five unique mutations $\left({ }^{\mathrm{L}} 25^{\mathrm{S}},{ }^{\mathrm{I}} 70^{\mathrm{V}}, \mathrm{C}_{107} 10 \mathrm{~F}^{\mathrm{F}},{ }^{\mathrm{F}} 124^{\mathrm{L}}\right.$ and ${ }^{\mathrm{D}} 168^{\mathrm{N}}$ ) occurred in CHGD-01 (Figure 2b). These mutations might play an important role in the classification of the groups.

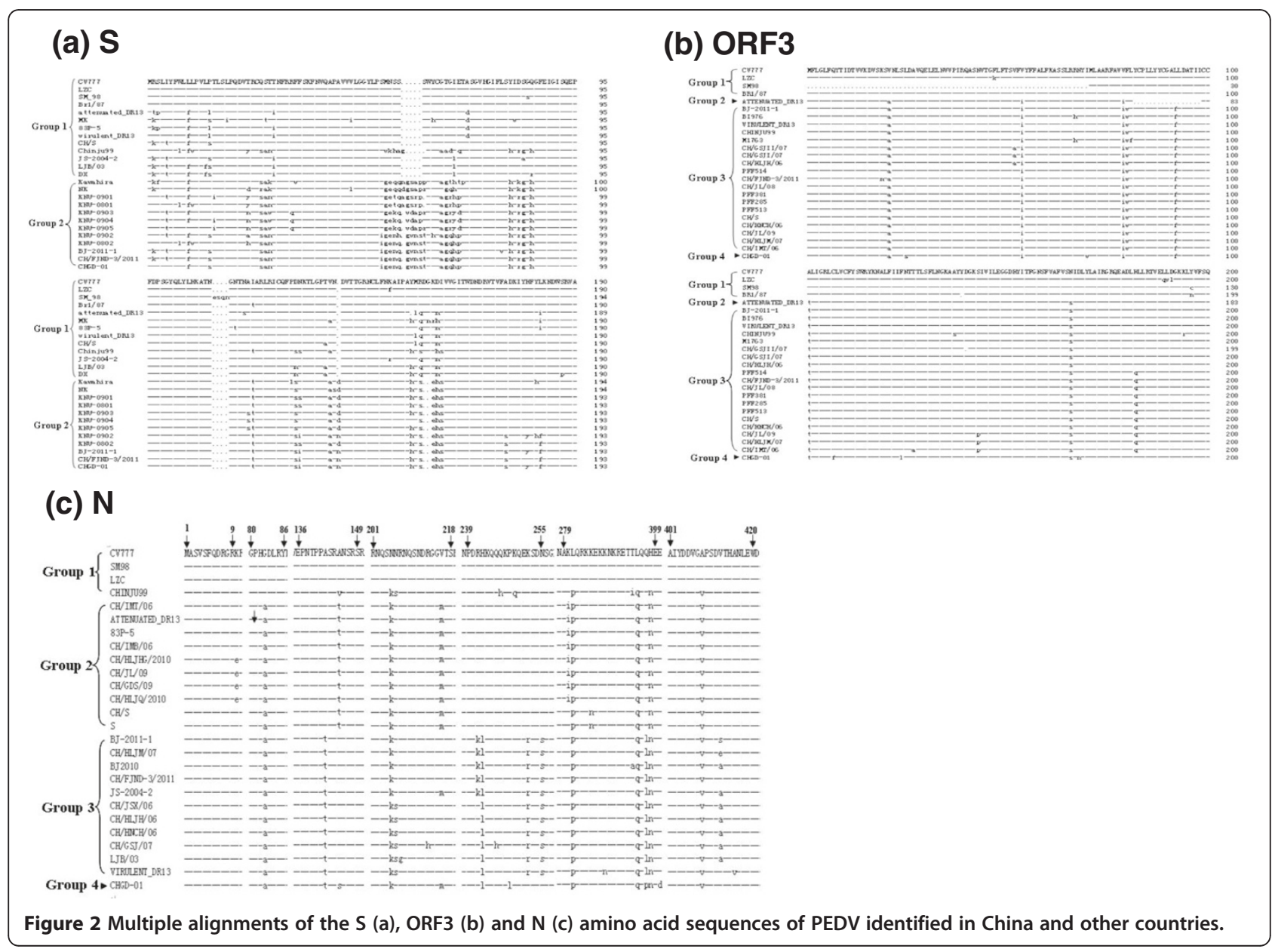




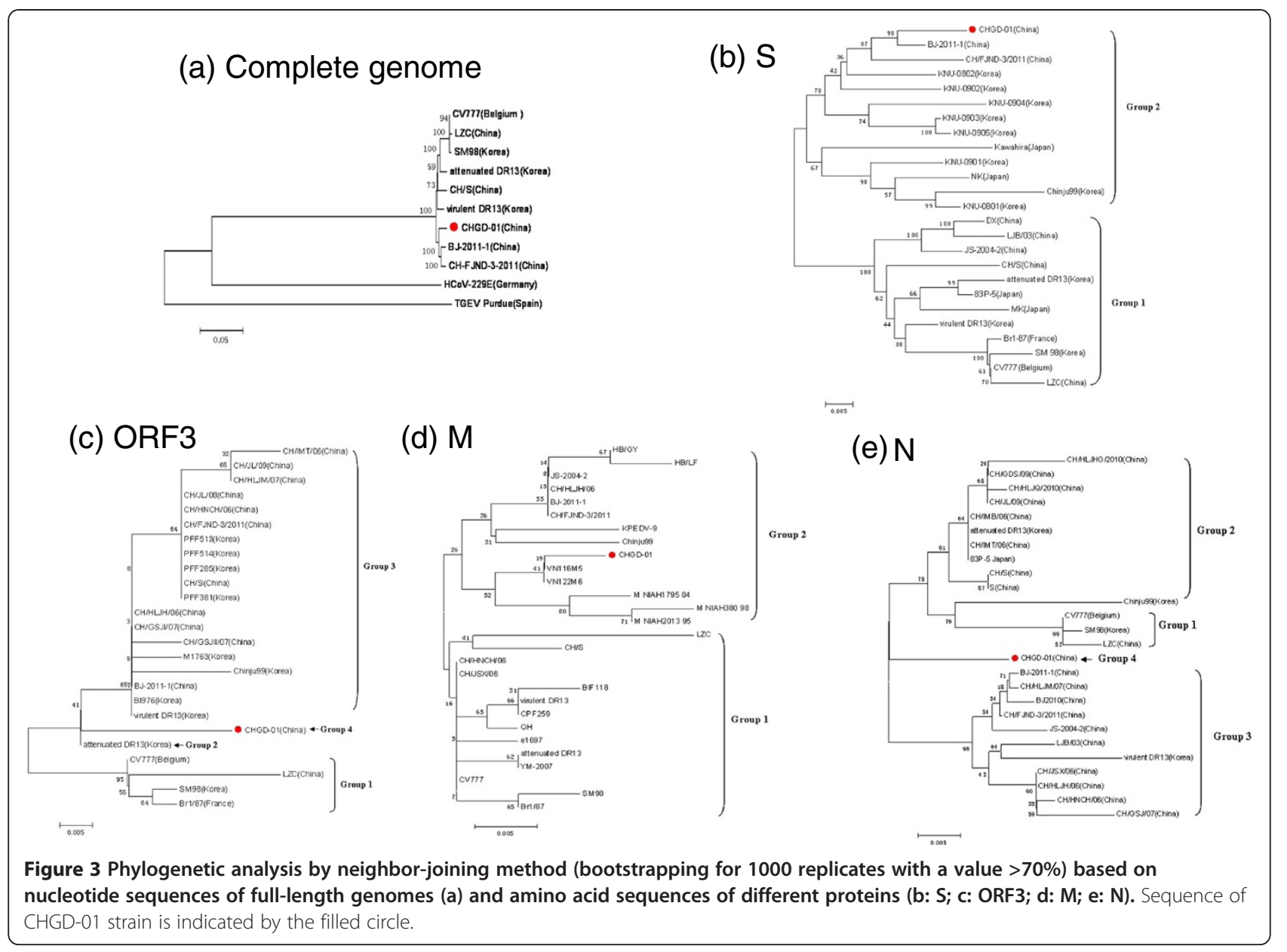

The M protein of CHGD-01 was found to be 226 amino acids long and highly conserved. It shared 96.999.5\% amino acid identity with the other PEDV strains. The highest amino acid identity (99.5\%) was with the Vietnamese field isolates (VN116M5 and VN116M6), which were isolated from southern Vietnam during the 2009-2010 PED outbreaks. Phylogenetic analyses demonstrated that all PEDV strains were similarly divided into two distinct genetic groups (Figure 3d). Group 1 comprised six Chinese strains (LZC, CH/S, $\mathrm{CH} / \mathrm{HNCH} / 06, \mathrm{CH} / \mathrm{JSX} / 06, \mathrm{QH}, \mathrm{YM}-2007)$, seven Korean strains (BIF118, CPF259, e1697, SM98, DR13 and its attenuated counterpart) and two European strains (CV777 and Brl/87). The CHGD-01 strain belonged to Group 2, which comprised seven Chinese strains (HB/GY, HB/LF, JS-2004-2, BJ-2011-1, CH/ FJND-3/2011, CHGD-01), two Korean strains (KPEDV9 and Chinju99), the recent Vietnamese strains (VN166M5 and VN122M6) and Thailand strains (NIAH1795, NIAH380 and NIAH2013). Previous studies suggested that JS-2004-2 was the ancestor of the Vietnamese and Thailand PEDV strains, and our results also demonstrated a close relationship between CHGD-01 and JS-2004-2.

The $\mathrm{N}$ gene of CHGD-01 was 1326 nucleotides in length, coding for a polypeptide of 441 amino acids. The amino acid sequence had $95.9-97.7 \%$ identity with other PEDV strains, and the highest identity (97.7\%) with the $\mathrm{CH} / \mathrm{S}$ and vaccine strains (attenuated DR13). Alignment analysis indicated that the entire nucleocapsid protein of CHGD-01 was generally highly conserved, but had 16 amino acid substitutions compared to CV777. It was predicted to contain eight potential serine (S)-linked phosphorylation sites and six potential threonine $(\mathrm{T})$-linked phosphorylation sites, including two protein kinase $\mathrm{C}$ phosphorylation sites, one casein kinase II phosphorylation site, and one cAMP- and three cGMP-dependent protein kinase phosphorylation sites. Based on analyses of the amino acid sequences of the PEDV $\mathrm{N}$ proteins, all PEDV strains could be divided into four groups (Figure 3e). CHGD-01 differed from all other PEDV isolates, and formed a new separate group. There were unique changes in the deduced amino acid sequences among the groups. Two amino 
acid changes $\left({ }^{\mathrm{A}} 145^{\mathrm{T}}, \mathrm{V}_{216^{\mathrm{M}}}\right)$ were found in Group 2;

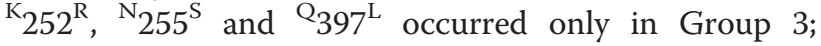
Groups 3, 4 shared two specific amino acid changes $\left({ }^{\mathrm{S}} 142^{\mathrm{T}}, \mathrm{H}_{242}{ }^{\mathrm{L}}\right)$; and ${ }^{\mathrm{G}} 84^{\mathrm{A}}$ was found in Groups 2, 3 and 4. Noticeably, six amino acid mutations $\left({ }^{\mathrm{A}} 145^{\mathrm{S}},{ }^{\mathrm{N}} 157^{\mathrm{S}}\right.$,

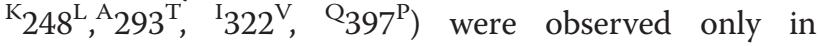
CHGD-01 (Figure 2c).

\section{Discussion}

The clinical signs from the outbreak in Guangdong, along with both macroscopic and microscopic examinations of the lesions, were strongly suggestive of PEDV or TGEV infection. TGEV and other possible pathogens were excluded and PEDV was therefore focused on as the only significant causative agent, followed by attempts to isolate it from piglets with the disease. PEDV was isolated successfully and propagated in Vero cell cultures in the presence of trypsin, according to the method described by Hofmann and Wyler, and by Kusanagi et al. [29,30]. However, the CPE caused by the PEDV isolate was not detected in Vero cells until after seven passages, despite being detectable by PCR. This was in contrast to the results of Hofmann and Wyler, who observed a CPE even at passage one in the same cells, and a prominent effect from virus passage five [29]. Kusanagi et al. reported that a characteristic CPE was detected at passage two, and became more evident with subsequent passages of Vero cells [30]. This discrepancy may be attributable to the relative susceptibilities of Vero cells to different isolates of PEDV.

To characterize the virus isolate, we determined the complete genomic sequence of CHGD-01 and analyzed the phylogenetic relationships among PEDV strains at the genomic and individual gene levels. The most variable regions were located in the $\mathrm{S}$ and ORF3 genes. The $\mathrm{S}$ protein is involved in receptor binding and virus entry, the induction of neutralizing antibodies, and host-cell fusion [18-20]. It is also an important target for monitoring the genetic diversity of coronavirus isolates [31,32]. Most PEDV reference isolates prior to 2007, including all Chinese strains, were partitioned into the first cluster (Group1; G1), whereas the three Chinese strains (CHGD-01, BJ-2011-1 and CH/FJND-3/2011) belong to the second cluster (Group 2; G2). All these three strains were isolated in 2011 when severe PED outbreaks were rampant in some areas of China. All Korean field strains belong to this cluster (except the Japanese isolates Kawahira and NK), most of which were isolated in 2008 and 2009. Interestingly, these three Chinese strains formed a unique cluster with the highest amino acid identities to KNU-0802 (96.5\%, 96.9\% and 96.2\%, respectively). In this study, the same amino acids insertions and deletion of the $\mathrm{S}$ gene were observed among three Chinese (CHGD-01, BJ-2011-1 and CH/FJND-3/2011) and two Korean (KNU-0802 and KNU-0902) strains. Both KNU-0802 and KNU-0902 were isolated in South Korea during 2008-2009. These results suggest that the recently isolated Chinese strains may have originated from Korean ones.

The ORF3 gene is situated between the $S$ and $E$ genes in the PEDV genome, but its function is unknown. Previous studies found that a continuous 49 or 51 nucleotide region was deleted within the ORF3 gene when PEDV was repeatedly passaged in cell culture, indicating a possible involvement in viral pathogenicity $[33,34]$. Recent investigations demonstrated that all the reported PEDV isolates could be classified into three groups, based on phylogenetic analyses of the ORF3 genes $[28,34]$. Our study notably revealed that the amino acid sequence of ORF3 in the CHGD-01 strain was clearly different from those of all other PEDV isolates. This difference could not be attributed to the effects of limited cellular passaging, because the ORF3 gene sequence of CHGD-01 passage 0 cells (i.e. intestinal fecal sample) was almost identical to that of passage 10 cells (data not shown). CHGD-01 fell out with the three previously identified groups, and thus constitutes a new group. The CHGD-01 isolate showed 93.3-95.1\%, 97.6\%, and 96.0-97.3\% amino acid sequence identities with members of Groups 1, 2 and 3, respectively. Genomic recombination is known to occur at high frequency between heterogenous genomes of coronaviruses. However, recombination analysis provided no evidence to suggest that CHGD-01 was derived directly from the recombination of known PEDV strains. Further molecular epidemiological evidence is needed to determine the origin and evolution of the CHGD-01 genome. The variations within the CHGD-01 genome, especially in the ORF3 and $\mathrm{S}$ genes, place it in a new cluster with BJ2011-1 and CH/FJND-3/2011, based on phylogenetic analysis of the PEDV genomes.

PED was generally considered to be under control or had only mild effects in swine herds in China before the beginning of 2011. Since then, however, PED has unexpectedly devastated many swine farms, including those were killed and attenuated vaccines based on CV777 were being used, suggesting that these vaccines were no longer able to confer protection. This raised the question of whether any obvious changes in antigenicity and/or virulence are associated with the genetic variations demonstrated in CHGD-01. The results of this study suggest that there is an urgent need for more fundamental research aimed at understanding the basic biology of this virus strain, as well as the mechanisms of immunogenicity and pathogenesis of PEDV. 


\section{Conclusion}

The present study isolated and identified a PEDV CHGD-01 strain from infected piglets in Guangdong in 2011. Analysis of the genetics and evolution of CHGD01 demonstrated significant genetic diversity compared to other PEDV reference strains, suggesting the presence of a new variant PEDV in China.

\section{Materials and methods \\ Case description}

Outbreaks of diarrhea were observed at a number of pig farms at different locations between January and March 2011. The cases were characterized by watery diarrhea, dehydration and vomiting, with $80-100 \%$ morbidity and $50-90 \%$ mortality in suckling piglets, whereas affected sows were characterized by diarrhea, anorexia, and depression, but recovered within 1 week. Breeding herds had been immunized with attenuated or killed PED-TGE combined vaccine produced in China in the fall and winter of the previous year. The PEDV component of this vaccine was based on the CV777 strain.

Sick or dead piglets aged 1-21 days were submitted for laboratory investigation. Necropsy examination of all piglets revealed that the small intestines were congested and filled with fluid, and were thin-walled as a result of severe mucosal atrophy. Microscopically, marked cytoplasmic vacuolation and exfoliation of enterocytes with subsequent shortening of villi were noted. Tissues and feces and/or blood were collected from live or dead animals submitted for polymerase chain reaction (PCR) detection to perform a surveillance.

\section{Screening for viral pathogens}

Samples from feces and intestine tissues were subjected to virological investigations for common viral swine pathogens such as PEDV, transmissible gastroenteritis virus (TGEV), porcine rotavirus (PRV), porcine circovirus 2 (PCV2) [35], porcine kobuvirus [36], and porcine bocavirus (PBoV) [37], using previously described methods.

\section{Virus isolation and identification}

Growth medium (GM) was Dulbecco's modified Eagle's medium (DMEM, Gibco, USA) supplemented with $10 \%$ heat-inactivated fetal calf serum, $0.3 \%$ tryptose phosphate broth (TPB), and antibiotics. Maintenance medium (MM) consisted of DMEM supplemented with $0.3 \% \mathrm{TPB}$ and $10 \mu \mathrm{g} / \mathrm{ml}$ trypsin (Gibco). Virus isolation was performed using Vero cells (CCL- $81^{\mathrm{ma}}$, ATCC), as described previously $[29,30]$ with minor modifications. Briefly, intestinal samples positive for PEDV by reverse transcription (RT)-PCR were further filtered through a $0.22-\mu \mathrm{m}$ syringe filter (Millipore, USA) and used as inoculum. GM was removed from confluent monolayer cell cultures, which were then washed twice with
DMEM and inoculated with the filtered intestinal content suspensions. After adsorption for $60 \mathrm{~min}$ at $37{ }^{\circ} \mathrm{C}$, the cells were washed with DMEM and MM was added. The Vero cell cultures were observed for 5 days for cytopathic effects (CPE).

Immunofluorescence assay (IFA) and electron microscopy were used to detect PEDV in the infected cells. The IFA utilized a 1:1000 dilution of mouse anti-S monoclonal antibody (Cat no: 9191, JBT, Korea) specific for PEDV and a 1:100 dilution of fluorescein isothiocyanate-conjugated goat anti-mouse IgG (Cat no: 02-18-06, KPL, USA). For electron microscopy, infected cell culture supernatants were partially purified by ultracentrifugation through a $20 \%$ (wt/wt) sucrose cushion, negatively stained with $2 \%$ ammonium molybdate, and examined with an electron microscope (JEM-1400, JEOL Ltd., Japan).

\section{Sequencing and sequence analysis}

Viral RNAs were extracted from CHGD-01-infected Vero culture supernatant using TRIzol LS reagent (Invitrogen, USA), according to the manufacturer's instructions.

Table 1 Primers used for sequencing reactions

\begin{tabular}{|c|c|c|}
\hline Oligonucleotides & Location $^{a}$ & sequence \\
\hline $1 \mathrm{~F}$ & 190-209 & GCGTTCCGTCGCCTTCTACA \\
\hline $1 \mathrm{R}$ & $2751-2729$ & CAGGAATCTGGAAGACACTTGCA \\
\hline $2 \mathrm{~F}$ & $2663-2684$ & GTATTATGCCACCAGTGTCCCA \\
\hline $2 R$ & 4957-4938 & CAGTTGCCAGCAGGCACTGT \\
\hline $3 \mathrm{~F}$ & 4887-4906 & ACCAGCGGTGCATTGCTTGA \\
\hline $3 R$ & 7475-7453 & CAATGTGCTCTTGCAATCCTGCA \\
\hline $4 \mathrm{~F}$ & $7327-7350$ & CTGTTAAGTTAGTGGACTCAGCGT \\
\hline $4 \mathrm{R}$ & $9875-9856$ & ACTAGCGCCTTCAACTTGCA \\
\hline $5 \mathrm{~F}$ & 9712-9731 & GCGCTTGTGGTTCACCTGGT \\
\hline $5 R$ & 12259-12240 & GGATCCACAGCGAAAGCGCA \\
\hline $6 \mathrm{~F}$ & $12182-12202$ & ACGCTTGCAGGCTGGTAAACA \\
\hline $6 \mathrm{R}$ & $14462-14442$ & TGGGCAGTGCTCTATCGCACT \\
\hline $7 \mathrm{~F}$ & $14322-14341$ & ATACTAGGGGCGCTTCGGTT \\
\hline $7 \mathrm{R}$ & $16780-16760$ & GTCAGGGTGCACAGGAATGAA \\
\hline $8 \mathrm{~F}$ & $16662-16684$ & GTATGTGTGCCCTTAAGCCTGAT \\
\hline $8 R$ & 19002-18980 & GTAAGTGGACGTTCGGCTTCATA \\
\hline $9 \mathrm{~F}$ & 18874-18898 & CGTAGCTITTGAGTTGTATGCCA \\
\hline $9 \mathrm{R}$ & 21330-21309 & GCAATTAGCTGTACAGGGTTCA \\
\hline $10 \mathrm{~F}$ & 21080-21101 & CCATTCCAGCTTATATGCGTGA \\
\hline $10 R$ & $23487-23465$ & GTACATGTGAAGCTTCTCAGCGT \\
\hline $11 \mathrm{~F}$ & $23272-23292$ & GTGTACGATCCTGCAAGTGGC \\
\hline $11 R$ & 25715-25694 & TCACCTCATCAACGGGAATAGA \\
\hline $12 \mathrm{~F}$ & $25535-25557$ & TCGTCCAATTGGTTAATCTGTGC \\
\hline $12 \mathrm{R}$ & $27840-27820$ & TACCGTTGTGTGCAAGACCAA \\
\hline 5' RACE Primer & $307-288$ & TTGCTAGCCATAGCCGGCAG \\
\hline 3'Race Primer & $27725-27747$ & CTATGTTCCAGGGTAGTGCCATT \\
\hline
\end{tabular}

aLocation corresponds to position within the CV777(AF353511) genome. 
Twelve pairs of oligonucleotide primers were used to amplify the different regions of the CHGD-01 genomes, and were designed based on the sequences of PEDV strain CV777. The PCR products were purified and cloned into
pMD18-T vector (TaKaRa, Japan) and sequenced using an automated genome sequence (Genetic Analyzer 3730XL; Applied Biosystems, USA). The terminal sequences were acquired using a kit for rapid amplification of cDNA ends

Table 2 PEDV strains investigated in this study

\begin{tabular}{|c|c|c|c|}
\hline Strain/Isolate & Accession No, Country & Strain/lsolate & Accession No, Country \\
\hline (a) Complete genome & & VN122M6 & HQ883484, Vietnam \\
\hline TGEV Purdue & AJ271965, Spain & Chinju99 & DQ845249, Korea \\
\hline $\mathrm{HCoV}-229 \mathrm{E}$ & AF304460, Germany & KPEDV-9 & AF015888, Korea \\
\hline CV777 & AF353511, Belgium & e1697 & FJ687454, Korea \\
\hline SM98 & GU937797, Korea & BIF118 & FJ687460, Korea \\
\hline attenuated DR13 & JQ023162,Korea & CPF259 & FJ687465, Korea \\
\hline Virulent DR13 & JQ023161, Korea & (d) N gene & \\
\hline LZC & EF185992, China & LJB/03 & DQ072726, China \\
\hline $\mathrm{CH} / \mathrm{S}$ & JN547228, China & JS-2004-2 & AY653206, China \\
\hline CH/FJND-3/2011 & JQ282909, China & $\mathrm{S}$ & DQ355223, China \\
\hline BJ-2011-1 & JN825712, China & $\mathrm{CH} / \mathrm{IMB} / 06$ & FJ473387, China \\
\hline CHGD-01 & JX261936, China & $\mathrm{CH} / \mathrm{JSX} / 06$ & FJ473388, China \\
\hline (b) S gene & & $\mathrm{CH} / \mathrm{HNCH} / 06$ & FJ473389, China \\
\hline $\mathrm{Br} 1-87$ & Z25483, France & $\mathrm{CH} / \mathrm{HLJH} / 06$ & FJ473390, China \\
\hline NK & AB548623, Japan & $\mathrm{CH} / \mathrm{IMT} / 06$ & FJ473391, China \\
\hline $\mathrm{MK}$ & AB548624, Japan & $\mathrm{CH} / \mathrm{HLJM} / 07$ & FJ473393, China \\
\hline $83 \mathrm{P}-5$ & AB548618, Japan & $\mathrm{CH} / \mathrm{GSJ} / 07$ & HM210880, China \\
\hline Kawahira & AB548622, Japan & CH/JL/09 & HM210881, China \\
\hline Chinju99 & AY167585, Korea & $\mathrm{CH} / \mathrm{GDS} / 09$ & HM210882, China \\
\hline KNU-0801 & GU180142, Korea & $\mathrm{CH} / \mathrm{HLJQ} / 2010$ & HQ455345, China \\
\hline KNU-0802 & GU180143, Korea & $\mathrm{CH} / \mathrm{HLJHG} / 2010$ & HQ455346, China \\
\hline KNU-0901 & GU180144, Korea & BJ2010 & JF690780, China \\
\hline KNU-0902 & GU180145, Korea & Chinju99 & AF237764, Korea \\
\hline KNU-0903 & GU180146, Korea & $83 P-5$ & AB618615, Japan \\
\hline KNU-0904 & GU180147, Korea & (e) ORF3 gene & \\
\hline$J S-2004-2$ & AY653204, China & $\mathrm{Br} 1 / 87$ & Z24733, France \\
\hline$\overline{D X}$ & EU031893,China & $\mathrm{CH} / \mathrm{HNCH} / 06$ & GU372738, China \\
\hline LJB-03 & DQ985739, China & $\mathrm{CH} / \mathrm{HLJH} / 06$ & GU372732, China \\
\hline (c) M gene & & $\mathrm{CH} / \mathrm{IMT} / 06$ & GU372739, China \\
\hline $\mathrm{Br} 1 / 87$ & Z24733, France & $\mathrm{CH} / \mathrm{GSJI} / 07$ & GU372737, China \\
\hline JS-2004-2 & AY653205, China & CH/GSJII/07 & GU372742, China \\
\hline $\mathrm{CH} / \mathrm{HLJH} / 06$ & EU033964, China & $\mathrm{CH} / \mathrm{HLJM} / 07$ & GU372735, China \\
\hline $\mathrm{CH} / \mathrm{HNCH} / 06$ & EU033963, China & CH/JL/08 & GU372734, China \\
\hline $\mathrm{CH} / \mathrm{JSX} / 06$ & EU033967, China & CH/JL/09 & GU372741, China \\
\hline YM-2007 & EU302820, China & Chinju99 & EU792474, Korea \\
\hline $\mathrm{QH}$ & AY974335, China & PFF285 & HQ537449, Korea \\
\hline $\mathrm{HB} / \mathrm{GY}$ & JN400910, China & PFF381 & HQ537451, Korea \\
\hline $\mathrm{HB} / \mathrm{LF}$ & JN400909, China & PFF513 & HQ537452, Korea \\
\hline M_NIAH380_98 & EU581712, Thailand & PFF514 & HQ537453, Korea \\
\hline M_NIAH1795_04 & EU542415, Thailand & M1763 & HQ537438, Korea \\
\hline M_NIAH2013_95 & EU581711, Thailand & $\mathrm{B} 1976$ & HQ537433, Korea \\
\hline VN116 M5 & HQ883483, Vietnam & & \\
\hline
\end{tabular}


(RACE) (Clontech, Japan). All primers are listed in Table 1. Sequence data were assembled and analyzed using Lasergene software (DNAstar Inc., USA). Multiple sequence alignments were performed using Clustal X 2.1 [38]. Phylogenetic analyses were carried out using the MEGA 4 program [39]. Phylogenetic trees based on the amino acid sequences of the S, ORF3, $\mathrm{M}$ and $\mathrm{N}$ proteins were elaborated using the neighbor-joining method, with bootstrapping over 1,000 replicates. The PEDV strains utilized in the present study including complete genome, S, ORF3, $\mathrm{M}$ and $\mathrm{N}$ genes are listed in Table 2, along with their GenBank accession numbers. Protein kinase-specific phosphorylation sites were identified using the prediction tool KinasePhos program through the web server (http://kinasephos.mbc. nctu.edu.tw/predict.php) [40]. The gene sequence was scanned for possible recombination events using the software package SimPlot (v 3.5.1), according to the methods described previously [41]. The genome sequence of CHGD-01 was registered in GenBank under the accession number JX261936.

\section{Abbreviations}

PEDV: porcine epidemic diarrhea virus; TGEV: porcine transmissible gastroenteritis virus; CPE: cytopathic effects; RT-PCR: reverse transcriptionpolymerase chain reaction; RNA: ribonucleic acid; DMEM: Dulbecco's modified Eagle's medium; TPB: tryptose phosphate broth; GM: growth medium; MM: maintenance medium; IFA: immunofluorescence assay.

\section{Competing interests}

The authors declare that they have no competing interest.

\section{Authors' contributions}

YFP, XYT, WL carried out most of the experiments and drafted the manuscript. FC, YHS critically revised the manuscript and the experimental design. QFZ, DDW and YZB contributed to the interpretation of the findings and revised the manuscript. All of the authors read and approved the final manuscript.

\section{Acknowledgements}

This work was supported by grants from the Special Project from Guangdong Science and Technology Department (no. 2010B090301020).

Received: 5 November 2011 Accepted: 5 September 2012 Published: 12 September 2012

\section{References}

1. Oldham J: Letter to the editor. Pig Farming 1972, Oct suppl:72-73.

2. Pensaert MB, de Bouck P: A new coronavirus-like particle associated with diarrhea in swine. Arch Virol 1978, 58:243-247.

3. Chasey D, Cartwright SF: Virus-like particles associated with porcine epidemic diarrhoea. Res Vet Sci 1978, 25:255-256.

4. Hess RG, Bollwahn W, Pospischil A, Heinritzi K, Bachmann PA: Current aspects in the etiology of viral diarrheas of swine: occurrence of infections with the epizootic viral diarrhea (EVD) virus. Berl Munch Tierarztl Wochenschr 1980, 93:445-449.

5. Pospischil A, Hess RG, Bachmann PA: Light microscopy and ultrahistology of intestinal changes in pigs infected with epizootic diarrhoea virus (EVD): comparison with transmissible gastroenteritis (TGE) virus and porcine rotavirus infections. Zentralbl Veterinarmed B 1981, 28:564-577.

6. Takahashi K, Okada K, Ohshima K: An outbreak of swine diarrhea of a new-type associated with coronavirus-like particles in Japan. Nihon Juigaku Zasshi 1983, 45:829-832.

7. Kweon CH, Kwon BJ, Jung TS, Kee YJ, Hur DH, Hwang EK, Rhee JC, An SH: Isolation of porcine epidemic diarrhea virus (PEDV) in Korea. Korean J Vet Res 1993, 33:249-254.
8. Chen JF, Sun DB, Wang CB, Shi HY, Cui XC, Liu SW, Qiu HJ, Feng L: Molecular characterization and phylogenetic analysis of membrane protein genes of porcine epidemic diarrhea virus isolates in China. Virus Genes 2008, 36:355-364.

9. Park SJ, Moon HJ, Yang JS, Lee CS, Song DS, Kang BK, Park BK: Sequence analysis of the partial spike glycoprotein gene of porcine epidemic diarrhea viruses isolated in Korea. Virus Genes 2007, 35:321-332.

10. Kubota S, Sasaki O, Amimoto K, Okada N, Kitazima T, Yasuhara H: Detection of porcine epidemic diarrhea virus using polymerase chain reaction and comparison of the nucleocapsid protein genes among strains of the virus. J Vet Med Sci 1999, 61:827-830.

11. Puranaveja $S$, Poolperm $P$, Lertwatcharasarakul $P$, Kesdaengsakonwut $S$, Boonsoongnern A, Urairong K, Kitikoon P, Choojai P, Kedkovid R, Teankum $K$, Thanawongnuwech $R$ : Chinese-like strain of porcine epidemic diarrhea virus, Thailand. Emerg Infect Dis 2009, 15:1112-1115.

12. Duy DT, Toan NT, Puranaveja S, Thanawongnuwech R: Genetic Characterization of Porcine Epidemic Diarrhea Virus (PEDV) Isolates from Southern Vietnam during 2009-2010 Outbreaks. Thai J Vet Med 2011, 41:55-64.

13. Pensaert MB, Debouck $P$, Reynolds DJ: An immunoelectron microscopic and immunofluorescent study on the antigenic relationship between the coronavirus-like agent, CV 777, and several coronaviruses. Arch Virol 1981, 68:45-52.

14. Bridgen A, Duarte M, Tobler K, Laude H, Ackermann M: Sequence determination of the nucleocapsid protein gene of the porcine epidemic diarrhoea virus confirms that this virus is a coronavirus related to human coronavirus $229 \mathrm{E}$ and porcine transmissible gastroenteritis virus. J Gen Virol 1993, 74(Pt 9):1795-1804.

15. Miller MJ: Summary of current nomenclature, taxonomy, and classification of various microbial agents. Viral taxonomy. Clin Infect Dis 1993, 16:612-613.

16. Murphy FA, Gibbs EPJ, Horzinek MC, Studdert MJ: Veterinary Virology: The Third Edition. Veterinary research commuications 2000, 24:470.

17. Egberink HF, Ederveen J, Callebaut $P$, Horzinek MC: Characterization of the structural proteins of porcine epizootic diarrhea virus, strain CV777. Am J Vet Res 1988, 49:1320-1324.

18. Bosch BJ, van der Zee R, de Haan CA, Rottier PJ: The coronavirus spike protein is a class I virus fusion protein: structural and functional characterization of the fusion core complex. J Virol 2003, 77:8801-8811.

19. Godet M, Grosclaude J, Delmas B, Laude H: Major receptor-binding and neutralization determinants are located within the same domain of the transmissible gastroenteritis virus (coronavirus) spike protein. J Virol 1994, 68:8008-8016.

20. Chang SH, Bae JL, Kang TJ, Kim J, Chung GH, Lim CW, Laude H, Yang MS, Jang YS: Identification of the epitope region capable of inducing neutralizing antibodies against the porcine epidemic diarrhea virus. $\mathrm{Mo}$ Cells 2002, 14:295-299.

21. de Haan CA, Kuo L, Masters PS, Vennema H, Rottier PJ: Coronavirus particle assembly: primary structure requirements of the membrane protein. J Virol 1998, 72:6838-6850.

22. Nguyen VP, Hogue BG: Protein interactions during coronavirus assembly. J Virol 1997, 71:9278-9284.

23. Saif LJ: Coronavirus immunogens. Vet Microbiol 1993, 37:285-297.

24. Hou XL, Yu LY, Liu J: Development and evaluation of enzyme-linked immunosorbent assay based on recombinant nucleocapsid protein for detection of porcine epidemic diarrhea (PEDV) antibodies. Vet Microbiol 2007, 123:86-92.

25. Rodak L, Valicek L, Smid B, Nevorankova Z: An ELISA optimized for porcine epidemic diarrhoea virus detection in faeces. Vet Microbiol 2005, 105:9-17.

26. Song DS, Yang JS, Oh JS, Han JH, Park BK: Differentiation of a Vero cell adapted porcine epidemic diarrhea virus from Korean field strains by restriction fragment length polymorphism analysis of ORF 3. Vaccine 2003, 21:1833-1842.

27. Woods RD: Efficacy of a transmissible gastroenteritis coronavirus with an altered ORF-3 gene. Can J Vet Res 2001, 65:28-32.

28. Park SJ, Kim HK, Song DS, Moon HJ, Park BK: Molecular characterization and phylogenetic analysis of porcine epidemic diarrhea virus (PEDV) field isolates in Korea. Arch Virol 2011, 156:577-585. 
29. Hofmann M, Wyler R: Propagation of the virus of porcine epidemic diarrhea in cell culture. J Clin Microbiol 1988, 26:2235-2239.

30. Kusanagi K, Kuwahara H, Katoh T, Nunoya T, Ishikawa Y, Samejima T, Tajima $\mathrm{M}$ : Isolation and serial propagation of porcine epidemic diarrhea virus in cell cultures and partial characterization of the isolate. J Vet Med Sci 1992, 54:313-318.

31. Matsuyama S, Taguchi F: Receptor-induced conformational changes of murine coronavirus spike protein. J Virol 2002, 76:11819-11826.

32. Wang Fl, Fleming JO, Lai MM: Sequence analysis of the spike protein gene of murine coronavirus variants: study of genetic sites affecting neuropathogenicity. Virology 1992, 186:742-749.

33. Park SJ, Moon HJ, Luo Y, Kim HK, Kim EM, Yang JS, Song DS, Kang BK, Lee CS, Park BK: Cloning and further sequence analysis of the ORF3 gene of wild- and attenuated-type porcine epidemic diarrhea viruses. Virus Genes 2008, 36:95-104

34. Chen J, Wang C, Shi H, Qiu H, Liu S, Chen X, Zhang Z, Feng L: Molecular epidemiology of porcine epidemic diarrhea virus in China. Arch Virol 2010, 155:1471-1476.

35. Ogawa H, Taira O, Hirai T, Takeuchi H, Nagao A, Ishikawa Y, Tuchiya K, Nunoya T, Ueda S: Multiplex PCR and multiplex RT-PCR for inclusive detection of major swine DNA and RNA viruses in pigs with multiple infections. J Virol Methods 2009, 160:210-214.

36. Wang C, Lan D, Hua X: Porcine kobuvirus from pig stool specimens in Shanghai, China. Virus Genes 2011, 43:350-352.

37. Zhai S, Yue C, Wei Z, Long J, Ran D, Lin T, Deng Y, Huang L, Sun L, Zheng $H$, et al: High prevalence of a novel porcine bocavirus in weanling piglets with respiratory tract symptoms in China. Arch Virol 2010, 155:1313-1317.

38. Thompson JD, Gibson TJ, Plewniak F, Jeanmougin F, Higgins DG: The CLUSTAL_X windows interface: flexible strategies for multiple sequence alignment aided by quality analysis tools. Nucleic Acids Res 1997, 25:4876-4882

39. Tamura K, Dudley J, Nei M, Kumar S: MEGA4: Molecular Evolutionary Genetics Analysis (MEGA) software version 4.0. Mol Biol Evol 2007, 24:1596-1599

40. Huang HD, Lee TY, Tzeng SW, Horng JT: KinasePhos: a web tool for identifying protein kinase-specific phosphorylation sites. Nucleic Acids Res 2005, 33:W226-W229.

41. Lole KS, Bollinger RC, Paranjape RS, Gadkari D, Kulkarni SS, Novak NG, Ingersoll R, Sheppard HW, Ray SC: Full-length human immunodeficiency virus type 1 genomes from subtype C-infected seroconverters in India, with evidence of intersubtype recombination. J Virol 1999, 73:152-160.

doi:10.1186/1743-422X-9-195

Cite this article as: Pan et al:: Isolation and characterization of a variant porcine epidemic diarrhea virus in China. Virology Journal 2012 9:195.

\section{Submit your next manuscript to BioMed Central and take full advantage of:}

- Convenient online submission

- Thorough peer review

- No space constraints or color figure charges

- Immediate publication on acceptance

- Inclusion in PubMed, CAS, Scopus and Google Scholar

- Research which is freely available for redistribution 